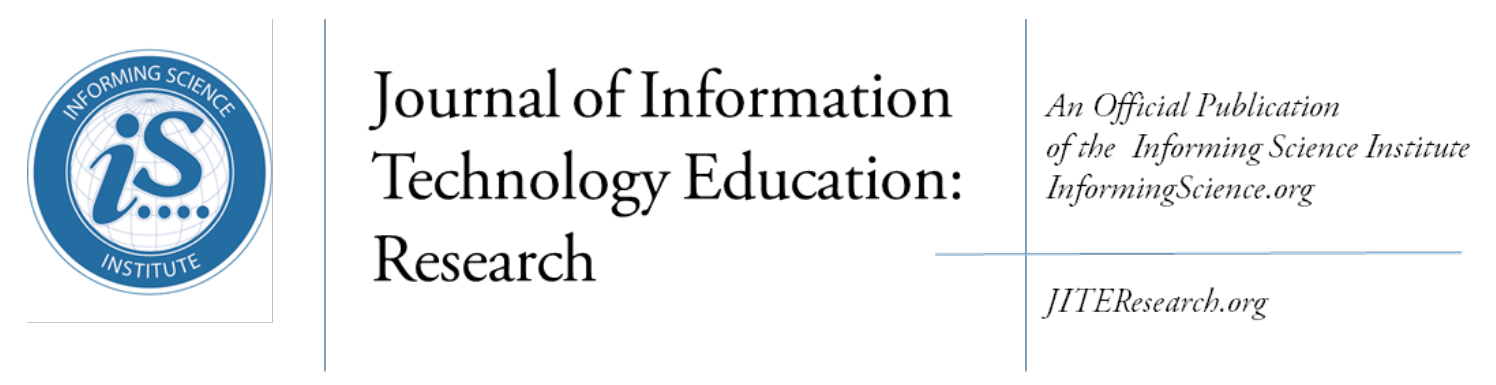

Volume 16, 2017

\title{
THE EFFECTS OF INSTRUCTIONAL DESIGN ON STUDENT ENGAGEMENT WITH VIDEO LECTURES AT CYBER UNIVERSITIES
}

\begin{tabular}{lll}
\hline Jamie Costley* & $\begin{array}{l}\text { Kongju National University, Gongju, } \\
\text { South Korea }\end{array}$ & costleyjamie@gmail.com \\
Christopher Hughes & $\begin{array}{l}\text { University of Birmingham, } \\
\text { Birmingham, United Kingdom }\end{array}$ & chris.jl.hughes@hotmail.com \\
Christopher Lange & $\begin{array}{l}\text { Joongbu University, Guemsam, } \\
\text { South Korea }\end{array}$ & christopherhlange@gmail.com \\
$*$ Corresponding author &
\end{tabular}

\begin{abstract}
Aim/Purpose

The number of students enrolled in online courses that use video lectures is on the rise. However, research shows that the number of students watching video lectures is low, and the number watching videos to completion is even lower.

Background This paper seeks to understand this problem by looking for correlations between instructional design and student engagement with video lectures.

Methodology

Students at a cyber-university in South Korea $(n=1801)$ were surveyed on their perception of the instructional design used in the courses they took and their engagement with online video lectures.

Contribution

This paper contributes to the body of knowledge by demonstrating positive correlations between instructional design, watching, and finishing video lectures.

Findings

While most other research has found low levels of online lecture viewership, this paper found significantly higher numbers watching and finishing videos. Other major findings of the paper are that five key elements of instructional design for online learning environments (designing methods, setting the curriculum, establishing time parameters, establishing netiquette, and utilizing the medium effectively) all correlated positively with students watching and finishing video lectures.
\end{abstract}

Accepting Editor: Minh Huynh | Received: October 3, 2016 | Revised: November 12, 2016; February 13, April 5, April 22, 2017 | Accepted: April 24, 2017

Cite as: Costley, J., Hughes, C., \& Lange, C. (2017). The effects of instructional design on student engagement with video lectures at cyber universities. Journal of Information Technology Education: Research, 16, 189-207. Retrieved from http://www.informingscience.org/Publications/3728

(CC BY-NC 4.0) This article is licensed to you under a Creative Commons Attribution-NonCommercial 4.0 International License. When you copy and redistribute this paper in full or in part, you need to provide proper attribution to it to ensure that others can later locate this work (and to ensure that others do not accuse you of plagiarism). You may (and we encourage you to) adapt, remix, transform, and build upon the material for any non-commercial purposes. This license does not permit you to use this material for commercial purposes. 
Recommendations Based on findings in this paper, it is recommended that practitioners consider for Practitioners taking actions when designing their instruction for online courses. These include batching their video lectures together by topic, devoting greater resources to helping students utilize the medium, and communicate time parameters in a way that encourages students to view video lectures in a timely manner.

Recommendation As the watching of video lectures in this study was mandatory for learners, an for Researchers interesting area of further research would be to examine whether that decision led to higher numbers of students watching them.

Future Research It is important for researchers to conduct further research into the interplay between ways instructors can design their instruction in order to encourage learners to better experience online learning.

Keywords instructional design, cyber university, video lectures

\section{INTRODUCTION}

The number of institutions offering e-learning environments as augmentations of and alternatives to traditional fully face-to-face classroom based learning experiences has rapidly increased in recent years (Lee \& Lee, 2015). E-learning courses are increasingly being initiated by institutions for their cost benefits (Bonk, Olson, Wisher, \& Orvis, 2002; Graham, Woodfield, \& Harris, 2003), embraced by instructors for the pedagogic benefits they offer (Morgan, 2002; Sorg et al., 1999), and sought out by learners for, among other factors, their flexibility, accessibility, and the opportunity to self-regulate their study paths (National Center for Education Statistics [NCES], 2008; Traphagan, 2005). The increasing student interest in e-learning courses is evident, as enrolment has steadily increased over the years (Allen \& Seaman, 2013; C. Kim \& Santiago, 2005; Korea Internet \& Security Agency, 2015; Korean Ministry of Education, Science \& Technology, 2010; S. Lim, 2014).

Although e-learning environments provide many of the same pedagogical functions as traditional ones, it is important for instructors and designers to be aware that there are significant differences (Al-Qahtani \& Higgins, 2013; Cole, Shelley, \& Swartz, 2014; Jung, 2000; Lee \& Rha, 2009). One major difference is the way in which instruction is designed. Instructional design (ID) considers the ways "the instructor, learners, materials, instructional activities, delivery system, and learning and performance environments interact and work with each other to bring about desired student learning outcomes" (Dick, Carey, \& Carey, 2015, p. 1). In e-learning environments, five facilitating elements of instructional design can be evaluated in order to decide whether ID has been effective. These are designing methods, setting the curriculum, establishing time parameters, establishing netiquette, and utilizing the medium effectively (Anderson, Rourke, Garrison, \& Archer, 2001). When these elements are perceived by learners to have been established in ways which positively facilitate and assist engagement and learning, a high level of instructional design can be said to be present. Conversely, when these elements are not set up in and communicated in such a way, low levels of instructional design can said to be present. Another integral part of many online courses is instruction or tutorials delivered via video recordings (Breslow et al, 2013.) While there has been a huge upswing in the number of courses offered and the number of students signing up for them, especially when cyber university courses are factored in, there appears to be a lack of significant engagement with these lectures by the learners they are supposed to serve (Clow, 2013). Engagement, for the purposes of this paper, means accessing and watching online video lectures as part of a course of study in an online program. Engagement with video material is important in learners' satisfaction with the course (J. Kim, Kwon, \& Cho, 2011; Zhan \& Mei, 2013), their likelihood of completing the course (Adamopoulos, 2013; Downes, 2010), and the likelihood that that they will wish to continue with elearning in the future (Giannakos, Jaccheri, \& Krogstie, 2015; Giannakos \& Vlamos, 2013). For these reasons, it is important to understand the relationship between instructional design and video lecture consumption. 
The purpose of this paper is to help address the lack of research on the relationship between instructional design and video lecture watching in online learning at cyber universities by presenting empirical evidence that shows how the student's perception of instructional design influences decisions to start and finish video lectures. The main research question this paper seeks to answer is: How does students' perception of instructional design correlate with their decisions to watch and finish video lectures?

This paper will address this question by first reviewing the theoretical background behind cyber universities, instructional design, video lectures, and student engagement with video lectures. Next, previous research related to the current study will be presented. This is followed by a methodology section. Next, results of the current study will be shown and followed by a discussion of their meaning and implication. A conclusion section summarizing the study will appear as the final section.

\section{THEORETICAL BACKGROUND}

\section{CYBER UNIVERSITIES IN KOREA}

South Korea has emerged as one of the leading proponents of e-learning driven by encouragement and generous government funding twined with the ready acceptance and embracing of advances in facilitating technology. This has led the number of students enrolling in courses offered by cyber universities to increase (C. Kim \& Santiago, 2005). Created as part of Korea's Lifelong Education Act, cyber universities were conceived in 1998 to provide fully online courses to university students as alternatives to perceived limits present in more traditional forms of higher education. Since the start of cyber university courses in 2001, there has been a dramatic increase in enrolment (C. Kim \& Santiago, 2005). Figures show that enrolment increased by 25\% between 2001 and 2010 (J. Kim, et al., 2011). Though some research into Korean online classes have claimed that the quality of instruction is "excellent" (Bae \& Jeon, 2014), there remains some questions as to the method of delivery and appropriateness in Korea (Im \& Kim, 2014). Furthermore, though there are claims of a significant paradigm shift in Korean education because of online learning (Yi, 2015), questions remain as to whether or not old offline patterns of teacher-centered instruction still remain the dominant paradigm.

\section{INSTRUCTIONAL DESIGN}

Differences between courses that are administered in brick and mortar environments and e-learning present challenges to the effective use of instruction designed to maximize online students' outcomes. Unlike offline learners, e-learners feel a sense of emotional and physical distance from their learning environments, which presents a major obstacle for online instructional designers to overcome if they want to avoid the potentially adverse effects it can cause, including decreased motivation and lack of interest (Lee \& Rha, 2009; Russo \& Benson, 2005). Effective instructional design can address this distance and potentially compensate for it in order to allow learners to maintain focus and motivation and to support them as they navigate their learning path. The absence of established forms of behavior and expectations in online learning platforms makes it necessary for instructors and designers to make their planning process as explicit and transparent as they can, as varying the levels of instructional design have been also shown to lead to higher or lower levels of student learning and satisfaction (Anderson et al., 2001; Costley \& Lange, 2016). As part of teaching presence within the Community of Inquiry (CoI) framework, the instructional design and organization component addresses these issues. Instructional design, as defined for the current study, is the development of instruction through the implementation of the following five elements: setting the curriculum, designing methods, establishing time parameters, establishing group norms, and utilizing the medium effectively (Anderson et al., 2001). Shea, Fredericksen, Pickett, and Pelz (2003) give a detailed explanation of what each element entails. Setting the curriculum promotes transparency of instruction through descriptive explanations of goals and desired outcomes. Designing methods includes the clear explanation of how to complete specific assignments and participate in learning 
tasks. Students are made aware of important due dates through the establishment of time parameters. Utilizing the medium effectively focuses on any issues the students may have with understanding how to use specific aspects of the online technology. Finally, establishing group norms helps ensure that the communication occurring within the online environment is socially acceptable. These instructional design elements serve as a means to provide students with a clear overall plan to succeed within the online environment.

\section{VIDEO LECTURES}

One way of counteracting the degree of distance felt by learners and reflecting effective instructional design is by providing quality video lectures. These can provide students with a sense of instructor presence, helping overcome the lack of real time physical and emotional interaction (Oomen-Early, Bold, Wiginton, Gallien, \& Anderson, 2008). Video lectures must, however, be designed and utilized correctly, if they are to be effective, and those that are not, can affect student outcomes negatively (Lin \& Chen, 2001). The use of new forms of media and technology must, according to Davis, Bagozzi, and Warshaw's (1989) Technology Acceptance Model (TAM), satisfy concerns over usefulness and ease of use. Acceptance and usage of course sites, and the video lectures therein, are aided by allaying these concerns (Selim, 2007).

\section{VIDEO LECTURE VIEWERSHIP}

The viewership of video lectures at cyber universities refers to the watching of video lectures by students who are enrolled in courses with associated video lectures. Regardless of size, there is a significant amount of data to show a discrepancy between the number of learners enrolling in e-learning courses and the number who watch the video lectures. Gorissen, Van Bruggen, and Jochem (2012) reported that, in a course at a Dutch university comprising of 34 videos, no individual viewer exceeded 20 views. McNulty et al. (2011) observed students enrolled in five separate course over the span of three cohorts, and found that less than one student in twenty watched a "large number" of videos and $64 \%$ watched less than $10 \%$ of video lectures. Stein and Allione (2014) found that, of approximately 36,000 students enrolled in a cyber-university course designed by Pennsylvania State University, less than 15,500 watched part of one video.

Focusing specifically on students' efforts to watch the entire video lecture, research has also investigated completion rates of videos among students who started watching the lectures. While studying the relationship between self-reporting and system analytics of videos watched by 5,000 learners at two different universities, Gorissen et al. (2012) found that the majority of enrollees neglected to sit through a single full lecture. Meanwhile, Guo, Kim, and Rubin (2014) found that more than 53\% of learners beginning a video ceased viewing before it ended. The majority of these instances occurred before the video's half way point. At the level of cyber universities, a study conducted by Guo et al. (2014) on 127,000 learners enrolled in an edX course found that, even discounting for dropouts in the first 5 seconds, $25 \%$ of viewers ceased viewing before completing $75 \%$ of video instruction.

\section{RELATIONSHIP BETWEEN INSTRUCTIONAL DESIGN AND STARTING TO WATCH VIDEO LECTURES}

Setting the curriculum as part of instructional design often includes communicating course outcomes and clearly stating how to achieve those outcomes (Shea et al., 2003). Making it clear to students if attendance is mandatory and part of assessment serves as one way of doing this, and doing so may have an impact on students' actual attendance. Parallels can be drawn between the attendance of lectures in traditional settings and the watching of video lectures in online courses, as watching the videos equates to "attending" the lectures within an e-learning course. The attendance of lectures in a traditional sense has been the subject of numerous studies (Friedman, Rodriguez, \& McComb, 2001; Marburger, 2001; Massingham \& Herrington, 2006; Moore et al., 2003; Purcell, 2007). At the top end of attendance, figures reported a range from 60 - 82.5\% (Friedman et al., 2001; Marburger, 2001; 
Massingham \& Herrington, 2006; Purcell, 2007; Romer, 1993). At the lower end, rates of 30\% (Moore et al., 2003) and even as low as 7\% (Massingham \& Herrington, 2006) have been reported. As Marburger's (2006) study of two groups enrolled in a macroeconomics course demonstrates, making the attendance of lectures mandatory does seem to have a positive correlation with increased attendance. This study showed that the class with a mandatory attendance policy had an average attendance that was $9.1 \%$ higher than the one in which attendance was not enforced. This is supported by further studies with similar results (Berenson, Carter, \& Norwood, 1992; Devadoss \& Foltz, 1996). However, other recent studies have suggested that penalties do not affect attendance as much as previously thought (Keen, 2006; Moore, 2003). Instead, the quality of instruction has far more of an impact on the students' decisions to attend lectures (Keen, 2006; Moore, 2003).

Setting and communicating curricula has long been known to positively affect learners' engagement with course materials (Tyler, 2013). If there is no clear rationale for participating in a course, engagement rates will be low (Phelps, Rosalie, Ashworth, \& Hahn, 1991), but if the rationale is clear, then higher engagement rates will be evident (Wisher \& Priest, 1998). Dykman and Davis (2008) demonstrated that learners are more likely to focus on learning when courses are clearly planned and offer clear expectations and guidelines. Evans, Baker, and Dee (2016) also demonstrated the importance, after investigating 2,900 lectures, of communicating topic and outcomes by "batching" similar content and clearly labeling it. Additionally, e-learning courses that utilize the mediums of instruction effectively by providing materials and instructional design that offers ease of use are more likely to stimulate engagement such as the watching of video lectures. It has been shown that it is important to optimize e-learning by providing learners with the training needed to control their learning (DeRouin, Fritzsche, \& Salas, 2004), that giving this kind of instruction can help with engagement (Brown \& Ford, 2002), and that a lack of knowledge about how to correctly utilize a distance platform can be the primary factor for program failure (Reeves, 1993). Darrington (2008) has pointed out that many students lack the tech savvy necessary to achieve desirable outcomes, while Magnussen (2008) showed that online training is necessary to address this issue and reduce learner frustration. Helping students become proficient at using specific e-learning platforms through specific instructional design techniques may impact their decision to engage in the platform. Liaw (2008) studied 424 students use of Blackboard and found that self-efficacy was key to satisfaction, which in turn promoted intention to use. Therefore, if instructors provide students with clear instruction on how to use specific video lecture platforms, that may have an effect on their decision to start watching the videos.

\section{RELATIONSHIP BETWEEN INSTRUCTIONAL DESIGN AND COMPLETING VIDEO LECTURES}

Instructors who design video lectures need to take into account the length of videos used for their learners. While videos that are too short may not engage the students enough, videos that are too long may keep students from completing the videos. The length of time learners spend watching lectures and the causes for this have been the source of some debate of late. Guo et al. (2014) investigated $6.9 \mathrm{~m}$ videos by analyzing the length of time learners spent on a video. They produced a much reproduced finding that the median engagement is 6 minutes. They also found that learners rarely watched more than half of videos that are nine minutes in length. Additionally, videos that are around 3 minutes in length received longer attention with $75 \%$ of sessions completing three quarters of these videos. Of significance to the current study is their conclusion that videos that were prepared especially for the online course and, therefore, display added levels of tailored instructional design were completed more often than videos that were designed for an alternative use and subsequently adapted.

The length of time spent watching a video may also be related to learners' ability to utilize the medium effectively. J. Kim et al. (2014) investigated 862 videos from 4 cyber university courses looking for data on in-video dropouts and peak activity. They found that there were more dropouts in longer videos. They used navigating away from the video before it had finished as a measure of engagement. This led 
to the discovery that $55 \%$ of learners dropped out across all videos. Interestingly, though, it was found that $37 \%$ of learners dropped out within the first $3 \%$ of the video. This quick dropout is ascribed to a number of instructional design possibilities that may have negatively affected the learners' ability to utilize the medium effectively including the following: auto-start, accidental start, misleading titles, or course navigation.

Instructional design considerations are key to learner engagement, specifically to engaging students enough to complete the video lectures. This is particularly the case when it comes to establishing time parameters. Successful instructional design of online classes is said to be related to the setting, pace, modulation of instruction, and tracking of due dates (Almala, 2007; Li \& Irby, 2008). Supporting the value of establishing time parameters, Geri, Gafni, and Winer (2014) describe the "U-shape" nature of video consumption over the course of a program. This means that more videos are watched at the beginning and end of a program than in the middle, and that the number watched at the end of a program was found to be the peak across all of the programs they analyzed. The high viewership at the end of the program was attributed to the students demonstrating their awareness of forthcoming assessment. Accordingly, clearly establishing time parameters may encourage students to completely watch videos because they are aware of deadlines involving assessment.

\section{The CuRrent STUdY}

Past research has shown that there is a problem when it comes to video lecture viewership, namely that not enough students are significantly watching the videos. This is evident in research showing that many students fail to even watch part of a video lecture (Stein \& Allione, 2014). Additionally, of the students who actually start watching the videos, research shows that a number of them do not complete all of the video lectures (Gorissen et al., 2012; Guo et al., 2014). One way of addressing this issue may be through effective use of instructional design. Although no research was found showing specific instructional design decisions that lead to students starting to watch videos, there is sufficient support from related studies to form hypotheses. First, research has shown that setting the curriculum has had a positive effect on attendance and engagement within offline courses (Berenson, et al., 1992; Devadoss \& Foltz, 1996; Dykman \& Davis, 2008 Marburger, 2006; Phelps, et al., 1991; Wisher \& Priest, 1998). Second, from an e-learning standpoint, instructional design aimed at utilizing the medium effectively has been shown to increase levels of engagement (DeRouin et al., 2004; Liaw, 2008). Additionally, designing video lectures that are a specific length has been shown to increase the chance that students will complete the lectures (Guo et al., 2014) and that getting students to use the platform effectively may influence their decision to continue watching the video lectures (J. Kim et al., 2014). Finally, establishing time parameters may be effective in getting students to complete the video lectures, as they anticipate assessment (Geri et al., 2014). This study seeks to answer the question of whether instructional design actually affects students' decisions to not only start watching video lectures, but also to complete them once they have started. Based on previous research, the following hypotheses are proposed:

\section{RESEARCH HYPOTHESES}

H1: Less than half of the respondents watched the video lectures.

H2: Less than $25 \%$ of the respondents completed a video.

H3: Instructional design is positively correlated with students starting the video lectures.

H4: Instructional design is positively correlated with students completing the video lectures.

It is predicted that results from the study presented in this study will demonstrate a relationship between instructional design, watching videos, and finishing videos. When instructional design is considered effective by learners, they will be more likely to begin watching videos and also finishing them. A figure visually representing this relationship can be seen below. In Figure 1, the oval represents instructional design. Effective instructional design correlates with watching and completing 
videos, as represented by the two boxes. Additionally, initially watching videos will also correlate with completion. This is demonstrated by the arrow between the Watching videos and Completing videos boxes. As can be also seen in Figure 1, the five instructional design indicators together load into the total instructional design construct.

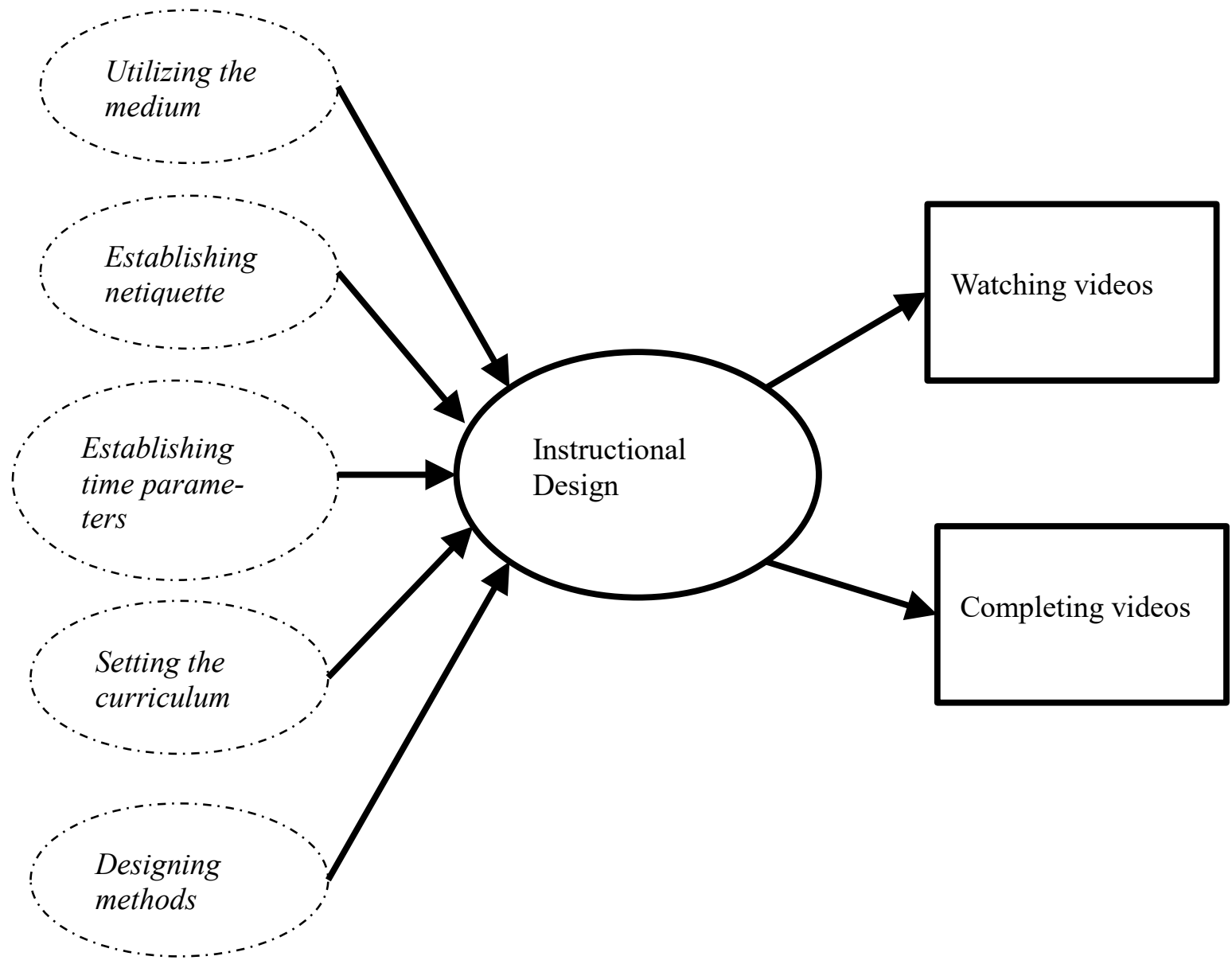

Figure 1. The indicators generating instructional design and instructional design affecting watching videos and completing videos

\section{METHODS}

\section{BACKGROUND TO THE OPEN CYBER UNIVERSITY}

This research looks at the effects of instructional design in the Open Cyber University of Korea (OCU). Participants that were a part of this study took OCU classes during the spring semester of 2016. The OCU was opened for classes in 1998, though its official founding is in 1997 (Jung \& Rha, 2001). To finance the OCU, a consortium of 23 traditional offline universities came together so that their students could take a wider variety of classes (Jung, 2000). The OCU is the largest provider of cyber university courses in Korea with more than 400 courses and serving more than 120,000 students each year ("About OCU," n.d.). The contents, courses, and instructors that form part of the OCU are provided by regular offline universities that make up the OCU (Jung \& Rha, 2001).Some classes offer offline meetups or offline assessment, though this is rare and most instruction, assessment, and interaction take place online, however the participants in this study took classes that were $100 \%$ online. 
OCU classes are available at no additional cost to students who are enrolled in offline courses in any of the offline member universities that make up the consortium. However, payment is required for

OCU students not enrolled in one of the member universities. Representing the largest cyber university consortium, the OCU offers more than 400 courses to approximately 120,000 students each year ("About OCU," n.d.). OCU classes are strictly taught online, with the exception of a few face-to-face offline meetings offered to students not enrolled in any of the member universities. Generally speaking however, OCU courses contain very little learner-to-learner interaction. Students who are enrolled at the member universities may take only one OCU class each semester (Jung \& Rha, 2001).

The member universities provide the design, direction, content, and instructors of the OCU courses. A council consisting of representatives selected by the member universities is in charge of policy creation within the OCU (Jung \& Rha, 2001). Additionally, instructional design and programming teams provide additional support to the instructors of the OCU courses. Finally, an evaluation team oversees the OCU, checking for aspects that may need help or further development ("About OCU," n.d.). The OCU runs its own learning management system. Though each class varies, there is space on the LMS for attendance, video lectures, forums, professor Q and A, quizzes, and supplementary audio and visual material (Han, 2012).

\section{DATA COLLECTION AND RESPONDENTS}

The beginning of the study included a series of short qualitative interviews with 10 students who had taken OCU classes in the second semester of 2015. The questions that formed a part of these interviews centered on the nature of learner-to-learner activities, the types of instruction that the students encountered, and how they felt instructional materials in the OCU affected their learning experience. A common comment from the interviews was that many students did not watch the videos. Though the videos are compulsory to watch, and students must click and start all videos as part of their participation grade, one of the original interviewees Kim's comment was typical, "I just turn on the lecture and do something else, like watch T.V. or my phone." Following that, a broad set of survey items was given to 92 students. This survey contained items ranging from cheating online to learner-to-learner interaction, to automated feedback systems. From this survey, several issues showed themselves to be relevant to students. Therefore, a more specific survey designed to be taken by a larger sample of students was developed. It is that second survey that is used for this study.

The survey was written in English first, and then later a Korean translation was created. This translation was evaluated by an expert in distance learning and the OCU. The translation was considered to be clear and an accurate translation of the English survey. This survey was put into a Google Sheets form and a link to the survey was sent to the OCU's administration. The OCU administration checked the contents of the survey and considered its appropriateness. Once the survey was accepted a link to the survey was posted on the main information board of the OCU, along with a message inviting the students to fill out the survey. The link was put the main board of the OCU in April of 2016. Students could fill out the form voluntarily and anonymously, by the time the survey was taken offline in May, 1801 students had submitted surveys.

From the 1801 surveys that were submitted, 180 were removed from the analysis used as part of this study as the respondents had failed to fill out the gender, age, start watching the lectures, complete watching the lectures, or instructional design items. This left 1621 valid respondents, of which 828 were female (51\%) and 793 were male (49\%). The oldest subject was 63 while the youngest was 15, with an average respondent age of 23.5. Among the respondents, they took a wide variety of classes in the OCU, though each participant in the study was taking only one class at the time of the experiment.

\section{INSTRUMENT DEVELOPMENT}

To create the measure to find out if the students started watching the video lectures, a single simple item was used. This item read, "Did you actually watch any of this week's lectures?" There were only 
two possible answers, "yes" or "no". To find out if the students completed watching the video lecture, another single item was used, which read, "Did you completely finish watching all of the lectures?" As with the other item, there were only two possible options for the students to select, "yes" or "no".

To generate the instructional design levels used in this study, five items from Shea et al. (2003) were used. These items are part of the instructional design and organization subcategory of teaching presence and include the items: Overall, the instructor for this course clearly communicated important course outcomes (for example, provided documentation on course goals); Overall, the professor for this course clearly communicated important course topics(for example, provided a clear and accurate course overview); Overall, the instructor for this course clearly communicated important due dates/time frames for learning activities that helped me keep pace with the course (for example, provided a clear and accurate course schedule, due dates, etc.); Overall, the instructor for this course helped me take advantage of the online environment to assist my learning (for example, provided instructions on how to navigate or use the online system); Overall, the instructor for this course belped students to understand and practice the kinds of behaviors acceptable in online learning environments (for example, how to communicate with the professor or students online). The respondents were asked to score between 0 and 10 how much they agreed with the previous statements. Once the items were created in English, they were translated into Korean and double-checked by an expert in teaching presence. Cronbach's Alpha for the three items was calculated to be .909 , which was deemed high enough to be used as a single construct.

\section{RESUlts}

To gain an overall picture of the main variables used in this study, means for instructional design and its component parts were examined. Overall the level of instructional design the students perceived was 6.27. This level of instructional design is similar to that found in other research using this particular construct (Shea et al., 2003). The lowest score for instructional design was 0.0 and the highest was 10, with a standard deviation of 2.19. Among the elements used to generate the instructional design construct, the one with the highest average was designing methods (6.87), followed by setting the curriculum (6.73), then establishing time parameters (6.44), and establishing netiquette (5.82), with utilizing the medium effectively (5.47) having the lowest average score among the elements that make up the instructional design construct (see Table 1).

Table 1. Descriptive statistics for instructional design $(n=1621)$

\begin{tabular}{lllll}
\hline & Min & Max & Mean & SD \\
\hline Instructional Design (ID) & 0 & 10 & 6.27 & 2.19 \\
Designing methods & 0 & 10 & 6.87 & 2.41 \\
Setting the curriculum & 0 & 10 & 6.73 & 2.42 \\
Establishing time parameters & 0 & 10 & 6.44 & 2.52 \\
Establishing netiquette & 0 & 10 & 5.82 & 2.76 \\
Utilizing the medium effectively & 0 & 10 & 5.47 & 2.64 \\
\hline
\end{tabular}

Of the 1621 students who were a part of this study, 1353 began watching the videos $(83 \%)$ and 242 did not even start watching the week's videos (17\%). Of those 1353 who began watching the videos, only 962 students answered that they completed watching the videos and 391 students answered that they did not complete watching the lectures. Furthermore, correlations were computed to see if there was any relationship between starting to watch the lectures, completing the lectures, gender, and age. As can be seen in Table 2, age was positively correlated with both beginning to watch the lectures and completing the lectures, that is, older participants were more likely to begin watching and, also, more likely to complete watching. 
Table 2. Correlations between watching the lectures, and age

\begin{tabular}{lll}
\hline \multicolumn{1}{c}{$n$} & Starting to watch the lectures & Completing the lectures \\
\hline Age $1621 \quad .062^{*}$ & $.082^{* *}$ \\
\hline \multirow{2}{**}{$=$ Correlation is significant at the 0.01 level (2-tailed) } \\
$*=$ Correlation is significant at the 0.05 level (2-tailed)
\end{tabular}

In Table 3, the results comparing gender were included. The results show there is a statistically significant difference between males and females. Males were less likely to watch the videos. Furthermore, of those that began, males were also less likely to complete watching the videos.

Table 3. Percentages of watching lectures by gender

\begin{tabular}{lllc}
\hline & Gender & Percentage & $p$-value \\
\hline Participants who started to watch the videos $(n=1352)$ & Male & $85 \%$ & .000 \\
& Female & $91 \%$ & \\
Participants who completed the videos $(\mathrm{n}=962)$ & Male & $76 \%$ & .000 \\
& Female & $86 \%$ & \\
\hline
\end{tabular}

Levels of instructional design were compared to see whether or not students started watching the lectures. As can be seen in Table 4, higher levels of instructional design are positively correlated with the students beginning to watch the lectures. Furthermore, the indicators that make up the instructional design construct were also compared with whether or not students started watching lectures. Every indicator was positively correlated with the students starting to watch the lectures.

\section{Table 4. Correlations between levels of instructional design and instructional design} indicators and participants starting to watch the lectures $(n=1621)$

$\begin{array}{llllll}(1) & (2) & (3) & (4) & (5) & \text { (6) }\end{array}$

1 Starting to watch lec- 1 tures

2 Instructional design $\quad .074 * * \quad 1$

3 Designing methods $\quad .064 * * \quad .842 * * \quad 1$

4 Setting the curriculum $\quad .050^{*} \quad .887^{* *} \quad .847^{* *} \quad 1$

5 Establishing time pa- $\quad .085^{* *} \quad .906^{* *} \quad .753^{* *} \quad .816^{* *} \quad 1$ rameters

6 Utilizing the medium $\quad .059 * \quad .808^{* *} \quad .494 * * \quad .547 * * \quad .641 * * \quad 1$ effectively

7 Establishing netiquette $\quad .074 * * \quad \begin{array}{llllll}.856^{* *} & .569^{* *} & .630^{* *} & .702^{* *} & .747 * * & 1\end{array}$

$* *=$ Correlation is significant at the 0.01 level (2-tailed)

$*=$ Correlation is significant at the 0.05 level (2-tailed)

Levels of instructional design were compared to whether or not students completed watching the lectures. As can be seen in Table 5, higher levels of instructional design are positively correlated with the students completing watching the lectures. Furthermore, the indicators that make up the instructional design construct were also compared with whether or not students completed watching the lectures. Every indicator was positively correlated with the students completing the lectures. 
Table 5. Correlations between levels of instructional design and instructional design indicators and participants completing the lectures $(n=1353)$

\begin{tabular}{|c|c|c|c|c|c|c|c|c|}
\hline & & 1 & 2 & 3 & 4 & 5 & 6 & 7 \\
\hline 1 & $\begin{array}{l}\text { Completing the lec- } \\
\text { tures }\end{array}$ & 1 & & & & & & \\
\hline 2 & Instructional design & $.104 * *$ & 1 & & & & & \\
\hline 3 & Designing methods & $.059 *$ & $.857^{* *}$ & 1 & & & & \\
\hline 4 & Setting the curriculum & $.077 * *$ & $.890 * *$ & $.859 * *$ & 1 & & & \\
\hline 5 & $\begin{array}{l}\text { Establishing time pa- } \\
\text { rameters }\end{array}$ & $.109 * *$ & $.909 * *$ & $.782^{* *}$ & $.828^{* *}$ & 1 & & \\
\hline 6 & $\begin{array}{l}\text { Utilizing the medium } \\
\text { effectively }\end{array}$ & $.084 * *$ & $.809 * *$ & $.513^{* *}$ & $.553^{* *}$ & $.634 * *$ & 1 & . \\
\hline 7 & $\begin{array}{l}\text { Establishing neti- } \\
\text { quette }\end{array}$ & $.092 * *$ & $.856^{* *}$ & $.586^{* *}$ & $.632 * *$ & $.699 * *$ & $.747 * *$ & 1 \\
\hline
\end{tabular}

** = Correlation is significant at the 0.01 level (2-tailed)

$*$ = Correlation is significant at the 0.05 level (2-tailed)

\section{DisCUSSION}

H1 predicted that "Less than half of the respondents watched the video lectures". This was not proven. In fact, $82 \%$ of learners clicked on and watched at least some of the video lectures. This is important as it goes against much of the current literature that suggests that video lectures are not widely watched (Gorissen et al., 2012; McNulty et al., 2011; Stein \& Allione, 2014). Active engagement with course material is desirable for the instructors, the institutions designing it, and the students in order to promote optimum outcomes. Therefore, the reasons for this difference are of keen importance. One reason for this discrepancy could well be the instructional design employed. As will be discussed below, this study included variables related to instructional design such as communicating outcomes and effective use of the medium. Results showed a positive relationship between these variables and watching video lectures.

The data did not support $\mathrm{H} 2$, which predicted that video lectures would be completed by less than $25 \%$ of students, as suggested by previous research (Gorissen et al., 2012; Guo et al., 2014; J. Kim et al., 2014). In the current research, $71 \%$ of learners who began watching the video lectures completed them. As with beginning to watch video lectures, this is highly significant as completing lectures was far exceeded in this study compared to any study reviewed in the current literature on this topic. The same variables related to instructional design that showed a positive relationship with beginning to watch video lectures also had a positive relationship with completing the lectures.

Interestingly, older students were more likely to both begin watching and completing video lectures. This could be an indication that older learners plan their time better so that they are able to watch and finish more video while studying in a self-determined schedule. It could also mean that younger learners have shorter attention spans resulting in them dropping out of videos early. A solution to this discrepancy could be for instructors to identify and react to differences by providing edited highlights of the instruction or possibly simplified slides separate from the video lectures.

H3 stated that instructional design is positively associated with students starting the video lectures. In this paper, instructional design is considered to be effective when the students perceive that the instructor has communicated key information to the students in a way that has helped them understand what is required in order for them to be successful. In other words, the instructor has provided 
the means to get them to learn (Dick et al., 2015). This type of instructional design is needed to give students a good understanding of the course and to facilitate engagement. The data supported $\mathrm{H} 3$ in that instructional design was positively correlated with students watching video lectures. As well as being positively correlated with instructional design as a combined construct, it was also positively corresponded with all constituent elements, as can be seen in Table 4. Other research had suggested that this would be the case. The importance of communicating curricula (Almala, 2007; Dykman \& Davis, 2008; Li \& Irby, 2008), communicating topics and outcomes (Evans, Baker, \& Dee, 2016), and using system and netiquette (Brown \& Ford, 2002; Darlington, 2005; DeRouin et al. 2004; Magnussen, 2008) have been shown to be important to learner engagement in previous studies examining different contexts. However, this appears to be the first study to demonstrate a positive correlation between students feeling positive about the instructional design employed and watching video lectures.

The variable designing methods had a positive relationship with beginning to watch videos. As part of this, outcomes, goals, and responsibilities, including the mandatory nature of watching videos would have been communicated. These findings suggest that, in the same way making and communicating the mandatory nature of attending traditional lectures increases attendance (Berenson et al., 1992; Devadoss \& Foltz, 1996; Marburger, 2006), making it clear that watching of video lectures is mandatory has a positive relationship with students at least beginning to watch them. As well as communicating the mandatory nature of attendance, setting and communicating curricula has been shown to have positive effects on learners' engagement in traditional educational environments by providing a clear rationale for participation, demonstrating that courses are clearly planned, and communicating topics (Dykman \& Davis, 2008; Evans et al., 2016; Phelps, Rosalie, Ashworth, \& Hahn, 1991; Tyler, 2013; Wisher \& Priest, 1998). The positive relationship reported in this study demonstrates that the same is true of courses offered by cyber universities.

The variable setting the curriculum had a positive relationship with starting to watch videos. This echoes Evans et al.'s (2008) study that showed that instructors can promote engagement by doing things like by "batching" and clearly labeling similar topics.

The variable utilizing the medium effectively had a positive correlation with starting to watch videos. This offers support to past studies which showed the importance of utilizing e-learning mediums of instruction in a way that allows learners to engage with them and optimize e-learning. DeRouin et al. (2004), Liaw (2008), and Magnussen (2008) emphasized the need for training learners to help students control their learning. Brown and Ford (2002) showed that this type of help can improve engagement. Reeves (1993) and Darrington (2008) showed that the absence of ability to navigate a platform leads to failure. This paper further adds to the debate by showing that a positive relationship between showing learners how to use a cyber-university content delivery platform can lead to high levels of video lecture viewership.

The other variables, establishing time parameters and establishing netiquette were also found to be positively related to watching video lectures. The positive relationship with establishing time parameters could be interpreted as showing the benefit of clearly communicating important dates such as deadlines, dues dates, and any quiz or exam days to students on their beginning to watch video lectures. It is harder to interpret the significance of a positive relationship with establishing netiquette. It could be that establishing group norms related to watching videos to allow for active participation in forums or discussions may have played a part, but this is an area for future focus.

H4 stated that "Instructional design is positively correlated with completing video lectures". This hypothesis was proven. Not only was the combined construct instructional design found to have a positive relationship with completing video lectures, but each of the individual variables also had positive relationships. This can be seen in Table 5 .

The variables designing methods and setting the curriculum had a positive relationship with completing videos. As was discussed in the literature review, the length of a video and whether it was developed as 
part of the instruction designed specifically for the online audience to which for whom it is being utilized play important roles in determining how likely a student is to complete a video lecture (Guo et al., 2014). The positive relationship demonstrated in this paper could be due to the communicating the need for engaging with video until the end and the development of engaging topics which made this more likely as these videos were developed specifically for students studying at the OCU. This supports the idea that, as part of instructional design, video lectures should be tailored to their audience and the fact that this is the case communicated to students.

The variable utilizing the medium effectively had a positive relationship with completing videos. This was also found to be the case by J. Kim et al. (2014). Their study showed that lack of ability to navigate an online platform led to learners navigating away from videos early. This reinforces the need stated above for learners to be assisted in becoming competent users of e-learning environments.

The variable establishing time parameters had a positive relationship with completing videos. This supports previous works that have demonstrated the importance of setting, pace, modulation, and tracking of due dates in online learning environments (Almala, 2007; Li \& Irby, 2008). The current study was not set up to ascertain when learners engaged with videos, so Geri et al.s (2014) "U-shape" described in the literature review could not be supported. The comparatively high number of students completing videos combined with the positive relationship shown between setting dates and those doing so suggests that, whenever learners are watching videos to completion, they are doing so in a timely manner.

As with starting to watch videos, the relationship with establishing netiquette was positive, but the significance of this is a still opaque. Again, it could be that a positive relationship suggests that learners are aware of their responsibilities as part of a community of inquiry as students of a cyber-university to complete lecture more often than has been shown in previous studies. Again, this is an area for future focus.

The five elements of instructional design used in this study are generally applied to online environments to provide students with clarity of the overall plan of the course. Furthermore, they are aimed at promoting focus and direction among students within their online learning process (Shea et al., 2003). The fact that students' perception of this type of instructional design was correlated with video lecture viewership is important within a general e-learning context, with particular importance being placed on the Korean context. University e-learning environments in general have been found to lead to low participation rates and often produce low levels of motivation and engagement (Yuan \& Powell, 2013). Maintaining student interest in watching video lectures is particularly critical in South Korea, where video lectures generally reflect teacher-centered lectures that occur in offline instruction (K. Lim, Kang, \& Park, 2016). This has been attributed to long-standing cultural norms, where Korean students are expected to be mere recipients of a one-sided lecture (K. Lim et al., 2016). Disregarding traditional norms of Korean learners may be a delicate issue, but designing video lectures to promote engagement and maintain their interest is a positive step for overcoming engagement issues of e-learning within a Korean context. It is apparent from this study that promoting Shea et al.'s (2003) instructional design elements addresses such engagement issues within a Korean context, as video viewership was positively correlated with those elements.

\section{CONCLUSION AND LIMITATIONS}

This study examined the engagement with video lectures by students enrolled in online courses at a cyber-university in South Korea by examining the relationship between watching video lectures and five elements of instructional design - setting the curriculum, designing methods, establishing time parameters, establishing group norms, and utilizing the medium effectively (Anderson et al., 2001). It was found that, while many other studies showed that a small number of video lectures were watched and ,of those that were watched, an even smaller number were completed, a large proportion of respondents said they had watched video lectures and also completed them. It was also found that instructional design positively correlated with both students watching video lectures and the videos 
being completed. The relationship between these constructs is similar to the one proposed in Figure 1. This study differs from previous work in that it sought to discover whether instructional design considerations could affect student engagement with video lectures. The engagement by students with video lectures has historically been low, while engagement has been shown to be of benefit. Therefore, discovering ways in which engagement with video lectures can be improved is a worthwhile endeavor. Previous studies have addressed the effect of instructional design on student engagement in traditional face-to-face contexts. Others have also addressed the effect of video design considerations such as length and the use of mixed media on knowledge transfer. Others still have considered the effect perceived ease of use and usefulness on engagement with online platforms. However, as far as the authors know, this is the first study to illustrate the correlation between instructional design and engagement with video lectures. The, so, what?, of this study is that the attention that instructors pay to ensuring their instructional design is effective for online learning environments can translate to increased student engagement with video lectures. At a time when online education is in the ascendancy as the go to form of instruction in many contexts, and one in which video lectures are a key component of instruction, consideration of how instructional design will affect student engagement with these resources and in these contexts is an important one.

\section{PRACTICAL IMPLICATIONS}

This study contributes to the discussion on using video lectures in online learning environments by pointing out the important effect of instructional design on students' engagement with a key means of delivering content: video lectures. This study is of use to instructional designers as it demonstrates the importance of getting key elements of instructional design right when creating online courses which use video lectures.

First, goals and outcomes need to be clearly described when instructors are setting the curriculum. This makes the value and purpose of engaging with video lectures clear. Second, when designing methods, learners need to be aware of how they should complete tasks and assignments. In the context of the study, watching video lectures was compulsory. A positive correlation between this variable and engagement with video lectures shows the importance of communicating this to students. Additionally, it is tentatively suggested that consideration be given to making the watching of video lectures compulsory and somehow linked to grading. Third, time parameters need to be established so that learners engage with video lectures in a timely manner and are aware of the lectures with which they need to engage with in time to meet due dates. Forth, and of critical importance, students need to be trained in how to effectively engage with the technology utilized as a medium of content delivery. This could be in the form of tutorial, workshops, or "how-to" guides. Finally, group norms and netiquette need to be established for learners engaging in online environments. In relation to watching video lectures, this could take the form of establishing how lectures could be consumed and how the content should be used in future discussions or assignments.

A final point to take away from this study is that younger and older students may engage with video lectures differently and alternatives could be considered to deliver content to younger students less able to cope with the freedom of self-directed study and therefore less likely to begin or complete video lectures.

\section{FUTURE AREAS OF RESEARCH}

Future areas of research to be considered involve isolating and examining in more detail the phenomena reported in this paper. Additionally, other factors affecting student engagement need to be further investigated. Most importantly, to what extent does making the watching of video lectures mandatory affect their viewing? It has been suggested in this paper that making mandatory the watching of video lectures promoted higher levels of engagement than in previous studies. An interesting piece of research for consideration would be the comparative study of engagement among students enrolled in online courses in which for one section watching videos is mandatory and for 
another it is not. Secondly, investigations of the five constructs of instructional design could be further investigated, in particular the most effective way to utilize the medium. A comparison of "how to", documents, tutorials, and workshops could, for example, be investigated. Lastly, further research into the content and production of video lectures is required. One areas of interest could be the effect of using mixed media on engagement.

\section{LIMITATIONS}

Although the results appear to be useful for e-learning instructional designers who wish to promote video viewership through instructional design decisions, there are limitations to this study. Primarily, the survey provided a snapshot of a particular set of students studying in a particular context. It is therefore limited in its generalizability. Caution should be applying these results to other contexts. Further research on different contexts is necessary in order to verify this study.

\section{REFERENCES}

About OCU (n.d.). In Open Cyber University. Retrieved from http://www.ocu.ac.kr/foreign/english/About ocu/sub05.asp

Al Qahtani, A. A., \& Higgins, S. E. (2013). Effects of traditional, blended and e-learning on students' achievement in higher education. Journal of Computer Assisted Learning, 29(3), 220-234.

Allen, I. E., \& Seaman, J. (2013). Changing course: Ten years of tracking online education in the United States. Newburyport, MA: Sloan Consortium.

Almala, A. H. (2007). Review of current issues in quality e-learning environments. Distance Learning, 4(3), 23-30.

Adamopoulos, P. (2013). What makes a great MOOC? An interdisciplinary analysis of student retention in online courses. Proceedings of the International Conference on Information Systems, 23-45.

Anderson, T, Rourke, L, Garrison, D. R., \& Archer, W (2001). Assessing teaching presence in a computer conferencing context. Journal of Asynchronous Learning Networks, 5(2), 1-17.

Bae, Y., \& Jeon, W. (2014). Analysis and improvement of online public lecture MOOC research. Korea Institute of Information and Communication Sciences, 18(12), 3005-3012.

Berenson, S. B., Carter, G., \& Norwood, K. S. (1992). The at-risk student in college developmental algebra. School Science and Mathematics, 92, 55-58.

Bonk, C. J., Olson, T. M., Wisher, R. A., \& Orvis, K. L. (2002). Learning from focus groups: An examination of blended learning. International Journal of E-Learning \& Distance Education, 17(3), 97-118.

Breslow, L., Pritchard, D. E., DeBoer, J., Stump, G. S., Ho, A. D., \& Seaton, D. T. (2013). Studying learning in the worldwide classroom: Research into edX's first MOOC. Research \& Practice in Assessment, 8 (March 2012), 13-25. Retrieved from http://www.rpajournal.com/dev/wp-content/uploads/2013/05/SF2.pdf

Brown, K. G., \& Ford, J. K. (2002). Using computer technology in training: Building an infrastructure for active learning. In K. Kraiger (Ed.), Creating, implementing, and managing effective training and development (pp. 192-233). San Francisco: Jossey-Bass.

Clow, D. (2013). MOOCs and the funnel of participation. Proceedings of the Third International Conference on Learning Analytics and Knowledge, 185-189.

Cole, M. T., Shelley, D. J., \& Swartz, L. B. (2014). Online instruction, e-learning, and student satisfaction: A three year study. The International Review of Research in Open and Distributed Learning, 15(6).

Costley, J., \& Lange, C. (2016). The effects of instructor control of online learning environments on satisfaction and perceived learning. The Electronic Journal of e-Learning 14(3). 169- 170. Retrieved from http://www.ejel.org/volume14/issue3/p169

Darrington, A. (2008). Six lessons in e-learning: Strategies and support for teachers new to online environments. Teaching English in the Two Year College, 35(4), 416-421. 
Davis, F. D., Bagozzi, R. P., \& Warshaw, P. R. (1989). User acceptance of computer technology: A comparison of two theoretical models. Management Science, 35(8), 982-1003.

DeRouin, R. E., Fritzsche, B. A., \& Salas, E. (2004). Optimizing e-learning: Research-based guidelines for learner-controlled training. Human Resource Management 43(23), 147-162.

Devadoss, S., \& Foltz, J. (1996). Evaluation of factors influencing student class attendance and performance. American Journal of Agricultural Economics, 78(3), 499-507.

Dick, W., Carey, L., \& Carey, J. O. (2015). The systematic design of instruction. New York: Pearson.

Downes, S. (2010). Learning networks and connective knowledge. Collective Intelligence and E-learning, 2, 1-26.

Dykman, C. A., \& Davis, C. K. (2008). Online education forum: Part two-Teaching online versus teaching conventionally. Journal of Information Systems Education, 19(2), 157-164.

Evans, B. J., Baker, R. B., \& Dee, T. S. (2016). Persistence patterns in massive open online courses (MOOCs). The Journal of Higher Education, 87(2), 206-242.

Friedman, P., Rodriguez, F., \& McComb, J. (2001). Why students do and do not attend class. College Teaching, 49, 124-133.

Geri, N., Gafni, R., \& Winer, A. (2014). The u-curve of e-learning: Course website and online video use in blended and distance learning. Interdisciplinary Journal of E-Learning and Learning Objects, 10, 1-16. Retrieved from https://www.informingscience.org/Publications/1959

Giannakos, M., Jaccheri, M. L., \& Krogstie, J. (2015). Exploring the relationship between video lecture usage patterns and students' attitudes. British Journal of Educational Technology. doi: 10.1111/bjet.12313

Giannakos, M. N., \& Vlamos, P. (2013). Educational webcasts' acceptance: Empirical examination and the role of experience. British Journal of Educational Technology, 44(1), 125-143.

Gorissen, P., Van Bruggen, J., \& Jochems, W. (2012). Usage reporting on recorded lectures using educational data mining. International Journal of Learning Technology, 7(1), 23-40.

Graham, C. R., Woodfield, W., \& Harrison, J. B. (2013). A framework for institutional adoption and implementation of blended learning in higher education. The Internet and Higher Education, 18, 4-14.

Guo, P. J., Kim, J., \& Rubin, R. (2014). How video production affects student engagement: An empirical study of MOOC videos. Proceedings of the first ACM conference on Learning at Scale. ACM, 2014.

Han, S. (2012). A study on the development of a course evaluation tool for Cyber University Consortium in Korea. In T. Kim, S. Mohammed, C. Ramos, J. Abawajy, B. Kang, \& D. Slezak (Eds.), Proceedings of Computer Applications for Web, Human Computer Interaction, Signal and Image Processing, and Pattern Recognition, 331-337.

Im, G., \& Kim, M. (2014). A SWOT analysis of design elements of Korean MOOCs. Digital Convergence Research 12(6), 615-624.

Jung, I. (2000). Korea: Virtual university trial project. TechKnowLogia, 29-31.

Jung, I., \& Rha, I. (2001). A virtual university trial project: Its impact on higher education in South Korea. Innovations in Education and Teaching International, 38(1), 31-41.

Keen, T. L. (2006). What are the perceptions of lecturers and students as to the place of the mass lecture in undergraduate education courses? Wollongong, NSW, Australia: Unpublished Honours thesis.

Kim, C., \& Santiago, R. (2005). Construction of E-learning environments in Korea. Educational Technology Research and Development, 53(4), 108-115.

Kim, J., Guo, P. J., Seaton, D. T., Mitros, P., Gajos, K. Z., \& Miller, R. C. (2014). Understanding in-video dropouts and interaction peaks in online lecture videos. Proceedings of the first ACM conference on Learning@scale conference (pp. 31-40). ACM.

Kim, J., Kwon, Y., \& Cho, D. (2011). Investigating factors that influence social presence and learning outcomes in distance higher education. Computers \& Education, 57(2), 1512-1520. Retrieved from http://doi.org/10.1016/i.compedu.2011.02.005 
Korea Internet \& Security Agency. (2015). Korea Internet White Paper 2015. Korea Internet \& Security Agency (South Korea) Retrieved from https://www.sbs.ox.ac.uk/cybersecuritycapacity/system/files/Korea Internet WhitePaper2015.pdf

Korean Ministry of Education, Science and Technology. (2010). Statistics for cyber universities and distance lifelong education institutions. Department of lifelong vocational education. Retrieved from http://www.mest.go.kr/me kor/chember/life/data/1263055 10974.html

Lee, H., \& Lee, S. (2015). Analysis of various influences and factors on academic persistence of cyber university students. International Journal of Service, Science and Technology 8(10), 211-222.

Lee, H. J., \& Rha, I. (2009). Influence of structure and interaction on student achievement and satisfaction in Web-based distance learning. Educational Technology \& Society, 12(4), 372-382.

Li, C., \& Irby, B. (2008). An overview of online education: Attractiveness, benefits, challenges, concerns and recommendations. College Student Journal, 42(2), 449-458.

Liaw, S. S. (2008). Investigating students' perceived satisfaction, behavioral intention, and effectiveness of elearning: A case study of the Blackboard system. Computers \& Education, 51(2), 864-873.

Lim, K., Kang, M., \& Park, S. Y. (2016). Structural relationships of environments, individuals, and learning outcomes in Korean online university settings. The International Review of Research in Open and Distributed Learning, 17(4).

Lim, S. (2014). 2014 White Paper on ICT in Education Korea. Korea Education and Research Information Service. Retrieved from http://english.keris.or.kr/whitepaper/WhitePaper eng 2014.pdf

Lin, K. M., \& Chen, N. S. (2001). Exploring learning problems of cyber university. Proceedings - IEEE International Conference on Advanced Learning Technologies, ICALT 2001 (pp. 369-370). Retrieved from http://doi.org/10.1109/ICALT.2001.943947

Magnussen, L. (2008). Applying the principles of significant learning in the e-learning environment. Journal of Nursing Education, 47(2), 82- 86.

Marburger, D. R. (2001). Absenteeism and undergraduate exam performance. Journal of Economic Education, 32, 99-110.

Marburger, D. R. (2006). Does mandatory attendance improve student performance? The Journal of Economic Education, 37(2), 148-155.

Massingham, P., \& Herrington, T. (2006). Does attendance matter? An examination of student attitudes, participation, performance and attendance. Journal of University Teaching and Learning Practice, 3(2), 82-103.

McNulty, J. A., Hoyt, A., Chandrasekhar, A. J., Espiritu, B., Gruener, G., Price, R., Jr., \& Naheedy, R. (2011). A three-year study of lecture multimedia utilization in the medical curriculum: associations with performances in the basic sciences. Medical Science Educator, 1(1), 29-36.

Moore, R. (2003). Attendance and performance: How important is it for students to attend class? Journal of College Science Teaching, 32, 367-371.

Moore, R., Jensen, M., Hatch, J., Duranczyk, I., Staats, S., \& Koch, L. (2003). Showing up: The importance of class attendance for academic success in introductory science courses. American Biology Teacher, 65, 325-329.

Morgan, K. R. (2002). Blended learning: A strategic action plan for a new campus. Seminole, FL: University of Central Florida.

National Center for Education Statistics. (2008). Distance education at degree-granting postsecondary institutions: 200607. US Department of Education. NCES 2009-044.

Oomen-Early, J., Bold, M., Gallien, T. L., Wiginton, K. L., \& Anderson, N. (2008). Using asynchronous audio communication (AAC) in the online classroom: A comparative study. MERLOT Journal of Online Learning and Teaching, 4(3), 267-276.

Phelps, R. H., Rosalie, A. W., Ashworth, R. L., Jr., \& Hahn, H. A. (1991), Effectiveness and costs of distance education using computer-mediated communication. American Journal of Distance Education, 5, 7-19. 
Purcell, P. J. (2007). Engineering student attendance at lectures: Effect on examination performance. Paper presented at The International Conference on Engineering Education, Coimbra, Portugal, September 3-7, 2007.

Reeves, T. C. (1993). Pseudoscience in computer-based instruction: The case of learner control research. Journal of Computer-Based Instruction, 20, 39-46.

Romer, D. (1993). Do students go to class? Should they? Journal of Economic Perspectives, 7, 167-174.

Russo, T., \& Benson, S. (2005). Learning with invisible others: Perceptions of online presence and their relationship to cognitive and affective learning. Educational Technology and Society, 8(1), 54-62. Retrieved from http://doi.org/ica proceeding 11822.PDF

Selim, H. M. (2007). Critical success factors for e-learning acceptance: Confirmatory factor models. Computers \& Education, 49(2), 396-413.

Shea, P. J., Fredericksen, E. E., Pickett, A. M., \& Pelz, W. E. (2003). A preliminary investigation of "teaching presence" in the SUNY learning network. Elements of Quality Online Education: Practice and Direction, 4, 279312.

Sorg, S., Truman-Davis, B., Dziuban, C., Moskal, P., Hartman, J., \& Juge, F. (1999). Faculty development, learner support and evaluation in Web-based programs. Interactive Learning Environments, 7(2-3), 137-154.

Stein, R. M., \& Allione, G. (2014). Mass attrition: An analysis of drop out from principles of microeconomics MOOC. PIER Working Paper, 14(031), 2014.

Traphagan, T. (2005). Class lecture webcasting, Fall 2004 and Spring 2005: A case study. University of Texas-Austin working paper.

Tyler, R. W. (2013). Basic principles of curriculum and instruction. University of Chicago Press.

Wisher, R. A., \& Priest, A. N. (1998), Cost-effectiveness of audio teletraining for the US Army National Guard. American Journal of Distance Education, 12(1), 38-51.

Yi, T. (2015). The study on KMOOC with the hub of ubiquitous knowledge sharing. Policy Issues, 14, 1-77.

Yuan, L., \& Powell, S. (2013). MOOCs and open education: implications for higher education [White Paper]. Retrieved from http://publications.cetis.ac.uk/2013/667

Zhan, Z., \& Mei, H. (2013). Academic self-concept and social presence in face-to-face and online learning: Perceptions and effects on students' learning achievement and satisfaction across environments. Computers \& Education, 69, 131-138.

\section{BIOGRAPHIES}

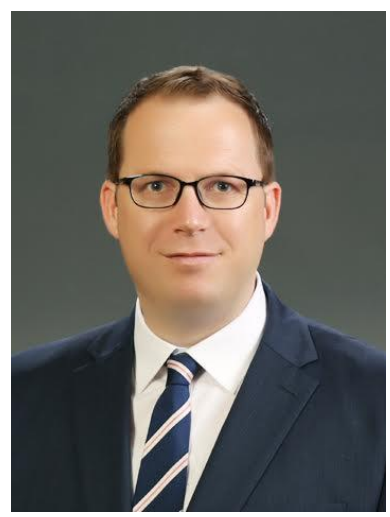

Jamie Costley earned his $\mathrm{PhD}$ in Instructional Design in the College of Education at Kongju National University, where he also works as a visiting professor. Dr. Costley has been involved in teaching students in blended learning situations and researching online instructional strategies since 2010. His main area of research is the impact of task or learning environment design on student-to-student interaction. Dr. Costley is currently involved in research into improving instruction in online classes in South Korea, and welcomes contact on this topic. 


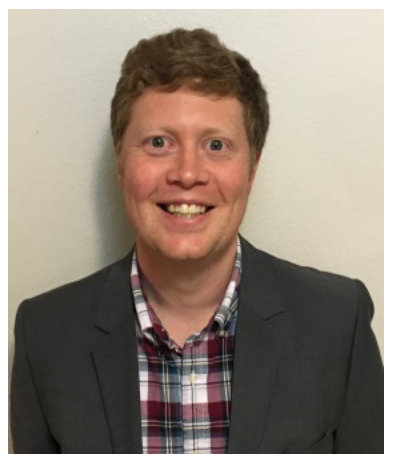

Christopher Hughes is an educator who has taught and researched effective hybrid instructional strategies since 2006. He holds an MA in Applied Linguistics from University of Birmingham. His main area of interest is how best to design online environments that maximize student engagement. He is currently researching how differing factors affect student engagement with online video lectures.

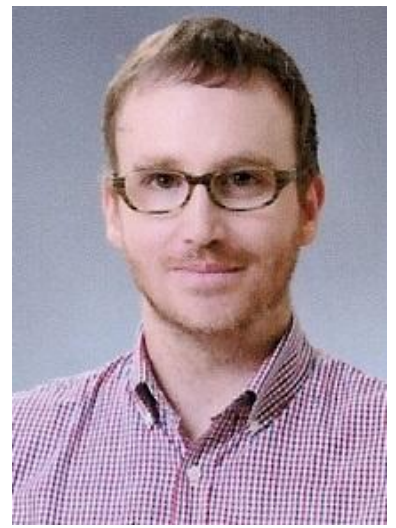

Christopher Lange is a visiting professor in the Liberal Arts department at Joongbu University in South Korea. He has published papers on group work and e-learning environments. His current research interests are the effects of interaction within online learning environments. Additionally, he is interested in investigating ways of improving online instruction, design, and delivery to better address the needs of e-learning students. He recently earned a $\mathrm{PhD}$ in Education from Kongju National University in South Korea. 